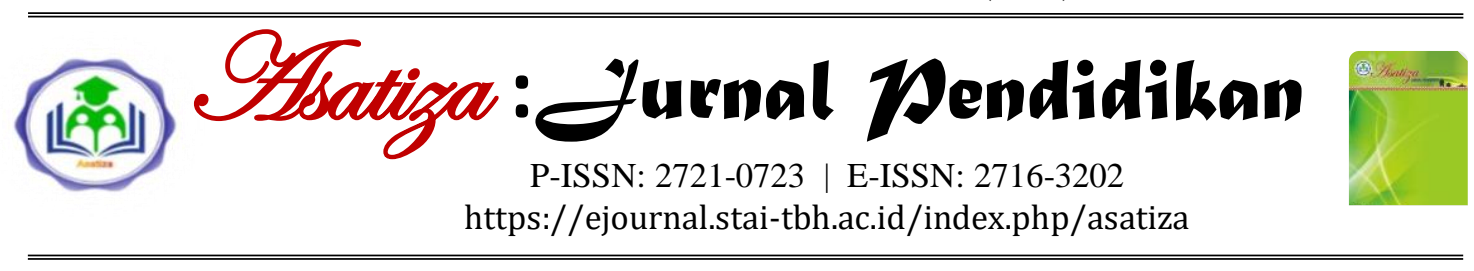

\title{
Implementasi Administrasi Fasilitas dan Ketenagakerjaan Laboratorium Bahasa di UIN Raden Mas Said Surakarta
}

\author{
*Sania Alfaini ${ }^{1, a}$, Siti Nurilngin ${ }^{2, b}$ \\ 1,2 UIN Raden Mas Said, Surakarta, Jawa Tengah, Indonesia \\ a shania.alfaini86@gmail.com, ${ }^{b}$ nurilnur08@gmail.com
}

\begin{tabular}{|c|c|}
\hline $\begin{array}{l}\text { INFORM } \\
\text { ARTIKEL }\end{array}$ & \\
\hline Histori Ar & tikel: \\
\hline Diterima & $: 11 / 10 / 2021$ \\
\hline Direvisi & : 03/01/2022 \\
\hline Disetujui & :04/01/2022 \\
\hline Diterbitkan & : 31/01/2022 \\
\hline
\end{tabular}

Keywords:

Administration, Infrastructure, Human Resources

Kata Kunci: Administrasi, Sarana Prasarana, Sumber Daya Manusia

\section{DOI:}

https://doi.org/10.46963/ asatiza.v3i1.406

*Correspondence

Author:

shania.alfaini86@gmail.c

\begin{abstract}
Infrastructure is essential to support learning, also an operational standard is needed to optimize the use of infrastructure in accordance with the objectives to be achieved. The purpose of this study was to determine the implementation of facility administration and employment in the language laboratory at UIN Raden Mas Said Surakarta. This research was descriptive qualitative, the data were collected using interviews, observation, and some related documents. The results of the study indicate that the administration of UIN Raden Mas Said already has special requirements in its management, that in the management of facilities and manpower administration it is carried out in accordance with the applicable standards.
\end{abstract}

\section{Abstrak}

Sarana prasarana menjadi penunjang penting dalam pembelajaran. Diperlukan sebuah standar operasional pengoperasian untuk mengoptimalkan penggunaan sarana prasarana sesuai dengan tujuan yang ingin dicapai. Tujuan penelitian ini yaitu untuk mengetahui implementasi administrasi fasilitas dan ketenagakerjaan di laboratorium bahasa di UIN Raden Mas Said Surakarta. Metode penelitian yang digunakan, yaitu kualitatif deskriptif, pengumpulan data diperoleh dengan cara observasi wawancara dan beberapa dokumen terkait. Hasil penelitian menunjukkan bahwa administrasi UIN Raden Mas Said sudah memiliki syarat khusus dalam pengelolaannya, bahwa dalam pengelolaan administrasi fasilitas dan ketenagakerjaan terlaksana sesuai dengan standar yang diberlakukan.

\section{Cara mensitasi artikel:}

Alfaini. S., \& Nurilngin, S. (2022). Implementasi administrasi fasilitas dan ketenagakerjaan laboratorium bahasa di UIN Raden Mas Said Surakarta. Asatiza: Jurnal Pendidikan, 3(1), 11-19. https://doi.org/10.46963/asatiza.v3i1.406.

\section{PENDAHULUAN}

Dalam melaksanakan sebuah pembelajaran, dibutuhkan beberapa faktor untuk menunjang terlaksananya tujuan pembelajaran, terutama pada pembelajaran bahasa yang banyak membutuhkan praktik, selain itu sarana dan prasaran juga menjadi penting untuk meningkatkan motivasi belajar. Hal tersebut tertuang dalam peraturan pemerintah nomor 57 tahun 2021 tentang Standar Nasional Pendidikan, disebutkan bahwa Standar sarana prasarana dilakukan untuk mencapai tujuan pembelajaran berdasarkan standar kriteria minimum yang telah ditentukan. Standar yang biasa diberlakukan untuk mengatur ketersediaan sarana prasarana suatu lembaga biasa disebut dengan Standar Operasional Prosedur (SOP). 
Menurut Fatimah (2016) SOP tidak hanya dibutuhkan sebagai pengelolaan sarana prasarana akan tetapi juga berkaitan dengan visi-misi yang akan dicapai oleh suatu lembaga. Sehingga dapat diartikan sebagai seperangkat peraturan yang telah disepakati oleh anggota lembaga untuk ditaati bersama demi kemajuan lembaga bersama. Pengelolaan SOP berkaitan dengan sarana prasarana, ketenagakerjaan hingga berbagai rangkaian kegiatan yang ada. SOP difungsikan untuk memudahkan suatu lembaga mengatur prosedur pelaksanaan yang ada. Dalam bidang pendidikan, SOP sangat dibutuhkan utamanya dalam mengelola sarana prasarana yang ada, seperti beberapa ruangan di suatu lembaga pendidikan yang memungkinkan menggunakan banyak alat seperti laboratorium.

Laboratorium merupakan salah satu fasilitas yang disediakan oleh suatu lembaga pendidikan untuk menunjang pembelajaran. Terdapat berbagai macam laboratorium disesuaikan dengan fungsinya, dalam bidang bahasa terdapat laboratorium bahasa. Seperti diketahui Priatmojo (2019) bahwa lab bahasa merupakan sarana sistem pengajaran bahasa yang dirancang menggunakan berbagai metode dan konsep. Disediakannya lab bahasa diharapkan dapat menunjang pembelajaran bahasa para peserta didik. Beberapa penelitian yang dilakukan, yakni oleh Kartika, Husni dan Millah (2019) menunjukkan bahwa motivasi siswa dapat dipengaruhi oleh kualitas sarana prasarana yang tersedia di lingkungan sekolah atau perguruan tinggi. Selain itu (Nurmalihah, 2010) juga mengungkapkan bahwa tersedianya laboratorium bahasa hendaknya juga dioptimalkan semaksimal mungkin agar pembelajaran dapat tercapai.

UIN Raden Mas Said merupakan salah satu universitas yang menyediakan sarana prasarana penunjang bagi mahasiswanya, pada bidang bahasa dibuatlah sebuah lembaga bernama Pusat Pengembangan Bahasa atau biasa disebut P2B. P2B inilah yang berperan sebagai lembaga pelatihan bahasa bagi para mahasiswa. P2B membawahi beberapa laboratorium yang ada di UIN Raden Mas Said Surakarta, salah satunya laboratorium bahasa. Untuk menjadikan sarana lab bahasa menjadi maksimal maka diperlukan pengelolaan yang efektif dan efisien.

Oleh karenanya, menggunakan suatu laboratorium bahasa tidak lepas dari suatu aturan atau tata tertibnya tersendiri yang dibuat berdasarkan undang-undang yang berlaku di suatu lembaga pendidikan tersebut maupun berdasarkan hasil kesepakatan dari beberapa pihak terkait. Dalam suatu lembaga pendidikan pasti ada penanganan, penataan serta penyusunannya, sama halnya dengan laboratorium bahasa yang ada di suatu lembaga pendidikan, ketiga hal tersebut pasti ada di dalamnya, hal tersebut telah dibuat dan disepakati oleh pihak yang berwenang dan harus dilaksanakan serta ditaati oleh semua pengguna laboratorium.

\section{METODE}

Jenis penelitian yang digunakan adalah penelitian kualitatif, yaitu penelitian untuk menganalisis sebuah masalah atau kejadian yang terjadi di lingkungan sosial, Adapun menurut Sugiono (2018) menjelaskan bahwa

\footnotetext{
12 Asatiza: Jurnal Pendidikan Vol. 3 No. 1 (2022)

12 This is an open access article under CC by SA License (https://creativecommons.org/licenses/by-sa/4.0)
} 
penelitian kualitatif adalah suatu metode yang digunakan untuk meneliti kondisi obyek pada lingkungan (secara ilmiah). Metode dalam penelitian ini menggunakan metode deskriptif, yaitu peneliti akan memanfaatkan data-data kualitatif kemudian dijabarkan secara deskriptif. Sumber data dalam penelitian ini merupakan subjek data-data yang valid dan relevan dengan teknik pengumpulan data berupa wawancara dan dokumentasi. Wawancara dilakukan kepada pranata laboratorium pendidikan UIN Raden Mas Said yang bernama Ibu Dwi dan Ibu Irma. Dokumentasi didapatkan melalui wawancara yang telah dilakukan.

Menurut Musthafa dan Acep (2018) menjelaskan bahwa observasi digunakan untuk pengumpulan data dengan cara mencari informasi dengan melihat kegiatan pada penelitian atau peristiwa yang berkaitan dengan masalah penelitian. Sedangkan teknik pengumpulan dokumentasi dilakukan guna mengumpulkan data atau dokumen dari berbagai hal media berupa catatan, transkrip, buku dan sebagainya. Pengumpulan data dilakukan di Laboratorium Bahasa UIN Raden Mas Said Surakarta.

Data hasil penelitian ini kemudian dianalisis menggunakan analisis interaktif. Teknik analisis ini dimulai dengan mereduksi data, yaitu merangkum, memilih hal-hal yang pokok dan memfokuskan pada hal-hal yang penting dari hasil wawancara (interviu) yang telah diperoleh. Setelah data direduksi, maka langkah selanjutnya adalah mendisplaykan (menyajikan) data, dengan teks yang bersifat naratif. Langkah ke tiga adalah menarik kesimpulan dan verifikasi.

\section{HASIL DAN PEMBAHASAN}

\section{Laboratorium UIN Raden Mas Said Surakarta}

UIN Raden Mas Said Surakarta berada di Jalan Pandawa, Pucangan, Kartasura, Sukoharjo. Fasilitas laboratorium di UIN Raden Mas Said Surakarta antara lain laboratorium multimedia, laboratorium bahasa, laboratorium fotografi, laboratorium penyiaran, laboratorium perbankan syariah, laboratorium ilmu hisab dan rukyah, dan laboratorium agama. Salah satu fasilitas yang penting dalam pengembangan bahasa mahasiswa dari segi kemahiran berbahasa Arab, yakni laboratorium bahasa. Sebagaimana definisi Walter dalam Priatmojo (2019) lab bahasa memiliki pengertian sebagai satu ruangan yang memiliki berbagai macam peralatan teknologi yang difungsikan untuk melatih ketrampilan berbahasa. Menurut Alexander dalam Priatmojo (2019) laboraturium bahasa memiliki beberapa definisi istilah lain di antaranya pusat sumber bahasa, laboraturium multimedia, pusat studi bahasa, pusat pembelajaran bahasa, pusat media interaktif, pusat belajar terbuka dan beberapa definisi istilah lainnya. Berdasarkan beberapa definisi yang dikemukakan para ahli dapat disimpulkan bahwa lab bahasa digambarkan sebagai suatu ruangan yang memanfaatkan teknologi untuk melatih suatu kelompok dalam meningkatkan ketrampilan berbicaranya. Seiring dengan perkembangan teknologi, pembelajaran bahasa tak lagi dilakukan secara 
tradisional dengan sistem ceramah, akan tetapi berinovasi menjadi sebuah laboraturium yang mewadahi ketrampilan berbahasa.

Pusat Pengembangan Bahasa (P2B) merupakan penunjang program dalam meningkatkan kemampuan berbahasa asing mahasiswa terutama Bahasa Arab. Fasilitas laboratorium bahasa di P2B merupakan tempat praktik dalam melatih berbahasa bagi mahasiswa, dosen, dan tenaga kependidikan. Adapun visi dari P2B UIN Raden Mas Said Surakarta, yakni menjadi lembaga penyedia yang unggul dalam mendukung visi UIN Raden Mas Said Surakarta yang berstandar internasional. Sedangkan misi dari P2B UIN Raden Mas Said Surakarta adalah menyelenggarakan pelayanan berbagai bahasa asing secara profesional dan berkualitas, menyelenggarakan proses belajar mengajar dan pelatihan bahasa asing yang efektif, komunikatif, dan efisien guna menghasilkan Sumber Daya Manusia (SDM) yang memiliki kompetensi bahasa untuk menguasai ilmu pengetahuan dan teknologi.

\section{Administrasi Fasilitas Laboratorium}

Berdasarkan hasil dari observasi bahwa P2B UIN Raden Mas Said Surakarta memiliki 10 ruang laboratorium bahasa. Sembilan ruang laboratorium laboratorium bahasa didalamnya terdiri 21 komputer dan adanya komputer master. Sedangkan satu ruang laboratorium bahasa dengan kapasitas 40 mahasiswa dan 1 dosen. Administrasi menurut Siagian (2011) dapat digambarkan sebagai hubungan yang melibatkan banyak orang, memiliki tujuan dan keinginan yang sama dan semua pemikiran didasarkan atas rasionalitas bersama. Administrasi laboratorium bahasa dapat didefiniskan sebagai suatu aturan yang dibuat secara bersama-sama oleh suatu lembaga untuk mencapai tujuan utama dalam pengoptimalan pembelajaran bahasa.

Administrasi ruang laboratorium merupakan pengelolaan laboratorium dari segi desain ruang laboratorium agar pemanfaatannya lebih optimal. Desain ruang laboratorium menurut Koesmadji \& Adisenja (2004), sebuah laboratorium dengan ukuran lantai seluas $100 \mathrm{~m}^{2}$ dapat digunakan oleh sekitar 40 siswa, dengan rasio setiap siswa menggunakan tempat seluas 2,5 $\mathrm{m}^{2}$ dari keseluruhan luas laboratorium. Desain laboratorium menurut Koesmadji dan desain laboratorium menurut Permendiknas memiliki persamaan dari keduanya adalah rasio setiap siswa dalam menggunakan tempat di laboratorium \pm sekitar $2,5 \mathrm{~m}^{2}$. Berdasarkan wawancara dengan Ibu Dwi selaku petugas dan ketenagaan laboratorium bahasa bahwa luas laboratorium bahasa di P2B UIN Raden Mas Said Surakarta sekitar $60 \mathrm{~m}^{2}$.

Adapun administrasi fasilitas laboratorium adalah pengelolaan laboratorium dari segi fasilitas umum maupun fasilitas khusus. Pada laboratorium bahasa P2B UIN Raden Mas Said Surakarta terdapat fasilitas umum yang dapat digunakan oleh semua pemakai laboratorium, yakni lampu sebagai penerangan. Sedangkan fasilitas khusus yang ada di laboratorium UIN Raden Mas Said Surakarta berupa peralatan-peralatan yang digunakan secara khusus seperti meja dosen, meja kursi, papan tulis. 
Administrasi alat dan perlengkapan laboratorium merupakan suatu kegiatan dan usaha untuk menyediakan rekaman tentang keadaan semua fasilitas, barangbarang yang dimiliki, serta mendata fasilitas atau menginventaris alat dan bahan laboratorium untuk kegiatan pembelajaran mahasiswa. Dapat didefinisikan sebagai rangkaian prosedur yang dilakukan untuk menunjang kegiatan pembelajaran dengan upaya pengoptimalan sumber daya manusia secara efektif dan efisien sesuai tujuan (Handani, 2019). Administrasi sarana prasarana meliputi perencanaan, pengadaan, penyimpanan, penyaluran, inventaris hingga penghapusan barang. Administrasi sarpras di lab bahasa meliputi jumlah ruangan, fasilitas yang tersedia dan juga beberapa peralatan yang ada dalam laboratorium. Inventarisasi yang dilakukan dalam hal administrasi ruang laboratorium sangat penting dilakukan karena bertujuan untuk mencegah kehilangan dan penyalahgunaan, mencegah pemakaian berlebihan, meningkatkan kerja sama. Berdasarkan data yang diperoleh dari staf P2B UIN Raden Mas Said Surakarta bahwa alat-alat yang ada dalam laboratorium bahasa di P2B UIN Raden Mas Said Surakarta antara lain meja dosen, kursi hadap, booth, kursi kelas, AC, speaker ruang, computer master, computer client, headset, LCD proyektor, LCD screen, UPS, lab controller, radio tape, monitor client, keyboard, printer, locker, stop kontak, jam dinding, peredam suara, tirai, lampu, papan tulis, tata tertib, dan karpet. Diketahui dari data tersebut, sarana dan prasarana yang ada di laboratorium bahasa P2B UIN Raden Mas Said Surakarta sudah sesuai dengan standar ruang laboratorium bahasa karena peralatan inti dari laboratorium meliputi komputer master dan booth.

\section{Administrasi Ketenagakerjaan \\ Laboratorium}

Administrasi petugas dan ketenagaan laboratorium berkaitan dengan pengelolaan ruang laboratorium oleh tenaga bantu di laboratorium, seperti teknisi laboratorium, asisten laboratorium atau laboran. Sumber daya manusia menjadi penting untuk diperhatikan, sebagaimana dalam suatu pustaka disebutkan bahwa suatu pengelolaan dapat berjalan apabila terdapat Man, Money, Material, Machine, Metode and Market. Sehingga tak dapat dipungkiri bahwasannya suatu administrasi ataupun manajemen membutuhkan kualitas SDM di dalamnya. Secara umum terdapat lingkup bahasan yang banyak pada SDM seperti Analisis pekerjaan, rekrutmen dan seleksi, kinerja pegawai, pelatihan dan pengembangan, dan lain-lain. Teknisi laboratorium adalah orang yang mendapatkan pendidikan pasca SMA jurusan sains dan matematik selama 1,2,3 tahun (diploma 1, 2, dan 3) dalam membantu pekerjaan di laboratorium. Sedangkan asisten laboratorium yang disebut laboran merupakan orang yang ahli dalam bekerja di laboratorium. Kualifikasi laboran telah ditetapkan pada Peraturan Menteri Pendidikan Nasional nomor 26 tahun 2008 dengan kriteria minimal lulusan program diploma satu (D1) yang relevan dengan jenis laboratorium, yang diselenggarakan oleh perguruan tinggi yang ditetapkan oleh 
pemerintah. Selain itu, kriteria lain memiliki sertifikat laboran sekolah atau madrasah dan perguruan tinggi yang ditetapkan oleh pemerintah. Berdasarkan wawancara dengan Ibu Dwi selaku petugas dan ketenagaan laboratorium bahasa bahwa tenaga kerja yang ada di laboratorium bahasa P2B UIN Raden Mas Said Surakarta hanya sebagai Pranata Laboratorium Pendidikan. Kualifikasi tenaga kerja untuk Pranata Laboran Pendidikan dan teknisi laboratorium di UIN Raden Mas Said diutamakan S1, S2, S3 prodi Pendidikan Bahasa Inggris, prodi Pendidikan Bahasa Arab, prodi Pendidikan Bahasa Indonesia, prodi Sastra Inggris, prodi Sastra Arab, dan prodi Sastra Indonesia. Rekruitmen petugas dan ketenagaan laboratorium yang di seleksi oleh pusat melalui seleksi CPNS. Tugas dari Pranata Laboratorium Pendidikan di P2B UIN Raden Mas Said Surakarta, yakni mengelola laboratorium bahasa dari penjadwalan, penggunaan laboratorium, penyusunan Standar Operasional Prosedur (SOP), pemeliharaan peralatan laboratorium, pendataan alat dan bahan laboratorium, dan penggunaan laboratorium baik untuk pengajaran penelitian maupun pengabdian masyarakat.

Administrasi kegiatan laboratorium merupakan pengelolaan laboratorium dari aspek kegiatan yang dapat dilakukan di Laboratorium, yakni mencakup kegiatan pengajaran, penelitian, dan pengabdian masyarakat. Kegiatan belajar mengajar antara mahasiswa dengan dosen terkait kemahiran berbahasa asing dengan adanya praktik mendengar dan berbicara menggunakan Bahasa Inggris maupun
Bahasa Arab. Kemahiran berbahasa dalam Bahasa Arab meliputi istima' kalam, qira'ah, dan kitabah. Mahasiswa dapat belajar bahasa Arab dengan praktik mendengarkan video berbahasa Arab lalu mengucapkan apa yang didengar. Dengan demikian, pembiasaan yang dilakukan secara terus menerus dapat menjadikan mahasiswa berkualitas dalam penguasaan bahasa asing. Sedangkan, ruang laboratorium bahasa juga digunakan untuk mendampingi warga dalam kegiatan yang berkaitan dengan praktik penggunaan bahasa.

Selanjutnya, selain administrasi laboratorium di atas, terdapat hal-hal yang harus diperhatikan dalam mengelola ruang laboratorium. SOP (Standar Operasional Prosedur) lab bahasa adalah suatu aturan yang berupa dokumen yang ada dalam suatu lab bahasa dalam bentuk prosedur agar proses penggunaan laboratorium bahasa dapat difungsikan secara efektif dan efisien sebagaimana dengan tujuannya (Priatmojo, 2019). Tujuan dari dibuatnya SOP laboraturium bahasa adalah untuk menjaga konsistensi performa lab bahasa, sebagai jaminan efisiensi penggunaan lab, sebagai dokumen yang digunakan dalam proses kegiatan pelatihan lab bahasa. Selain itu, terdapat manfaat dibuatnya SOP lab bahasa di antaranya sebagai pedoman kedisiplinan penggunaan lab bahasa, untuk menciptakan standar kerja yang digunakan sebagai acuan evaluasi kerja dan dimanfaatkan untuk menghindari tumpang tindih pemakaian lab bahasa. Pengelolaan dalam hal pengoperasian master laboratorium $1 \mathrm{di}$ P2B UIN Raden Mas Said Surakarta sebagai berikut: 
1. Tekan saklar utama pada bagian bawah tembok depan (belakang kursi dosen).

2. Nyalakan UPS dengan menekan tombol di sudut atas perangkat UPS. Jika UPS berbunyi lebih dari sekali, kemungkinan saklar master belum menyala atau listrik padam.

3. Nyalakan perangkat komputer master dengan menekan tombol power pada PC master.

4. Tekan saklar master laboratorium (bagian bawah meja komputer sebelah kanan) untuk mengaktifkan perangkat laboratorium.

5. Tekan tombol computer pada master laboratorium controller. Lampu indicator computer pada master laboratorium controller akan menyala, menandakan bahwa computer telah terhubung dengan perangkat laboratorium.

6. Untuk menghubungkan perangkat laboratorium dengan laptop, tancapkan kabel penghubung pada laptop. Selanjutnya tekan tombol laptop pada master laboratorium controller. Lampu indicator laptop pada master laboratorium controller akan menyala, menandakan bahwa laptop telah terhubung dengan perangkat laboratorium.

7. Selain computer dan laptop, perangkat laboratorium juga dapat dihubungkan dengan perangkat lain seperti telepon seluler, dengan cara menancapkan kabel penghubung pada telepon seluler. Selanjutnya tekan tombol pada master laboratorium controller. Lampu indikator pada master laboratorium controller akan menyala, menandakan bahwa telepon seluler telah terhubung dengan perangkat laboratorium.

8. Tekan tombol computer/laptop/ pada master laboratorium controller sekali lagi untuk memutuskan hubungan. Lampu indikator akan mati, menunjukkan bahwa perangkat laboratorium sudah tidak terhubung lagi.

9. Untuk mengaktifkan atau menonaktifkan monitor klien, tekan saklar sebelah kiri pada bagian bawah meja komputer. Gambar yang muncul pada monitor klien akan sama persis dengan gambar yang muncul pada monitor master.

Sedangkan berikut yaitu petunjuk pemutaran Audio :

1. Launching program yang diinginkan (winamp, VLC, atau media player lainnya) dengan cara klik dua kali pada icon program. Pilih file yang diinginkan. Kemudian klik play. Atau buka file yang diinginkan dengan cara klik dua kali, atau klik kanan lalu klik play with, pilih program yang akan dijalankan.

2. Klik icon speaker pada program dan/atau pada taskbar monitor untuk mengatur volume audio. Atau putar knob volume pada perangkat master laboratorium.

Adapun petunjuk tools master laboratorium sebagai berikut :

1. Untuk penggunaan speaker ruang, tekan tombol speaker. Pada mode ini audio akan keluar dari speaker ruang sehingga seluruh klien dapat mendengar. 
2. Untuk penggunaan headset, tekan tombol phone. Pada mode ini audio akan terdengar dari headset. Seluruh klien dapat mendengar audio yang diputar dan dapat berkomunikasi dengan headset master.

3. Putar knob mic siswa dan mic master untuk mengatur volume. Atau putar volume controller yang terdapat pada masing-masing headset.

4. Untuk penggunaan individu, tekan tombol individual, kemudian tekan nomor booth klien yang diinginkan. Pada mode ini audio terdengar dari headset seluruh klien namun hanya klien yang terhubung yang dapat berkomunikasi dengan headset master.

5. Untuk penggunaan individu secara privasi, tekan tombol individual dan inzo, kemudian tekan nomor booth klien yang diinginkan. Pada mode ini hanya klien yang terhubung yang dapat berkomunikasi dengan headset master sementara klien lain dapat mendengar audio yang diputar.

6. Klien dapat menekan tombol call pada booth untuk menginterupsi master. Pada perangkat master laboratorium, nomor booth klien yang menginterupsi akan berkedip. Tekan nomor tersebut untuk membuka komunikasi.

7. Untuk menutup komunikasi, tekan nomor booth klien yang diinginkan. Atau tekan close untuk menutup komunikasi dengan semua klien yang terhubung.

\section{SIMPULAN}

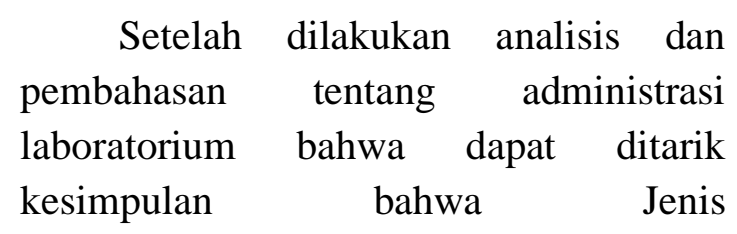

pengadministrasian dalam pengelolaan laboratorium bahasa di UIN Raden Mas Said Surakarta meliputi administrasi ruang laboratorium, administrasi fasilitas laboratorium, administrasi alat dan perlengkapan laboratorium, administrasi petugas dan ketenagaan laboratorium, administrasi kegiatan laboratorium.

Sedangkan inventarisasi peralatan dan perlengkapan yang ada di laboratorium bahasa P2B UIN Raden Mas Said Surakarta sudah baik dan memenuhi standar barang yang harus dimiliki oleh setiap laboratorium. Inventarisasi fasilitas, peralatan dan perlengkapan di laboratorium bertujuan untuk mencegah kehilangan dan penyalahgunaan barang yang ada di laboratorium. Serta kegiatan di laboratorium mencakup kegiatan pengajaran, penelitian, dan pengabdian masyarakat.

Adapun saran yang dapat direkomendasikan pada pihak-pihak terkait adalah membangun komitmen yang kuat terhadap manajemen universitas dalam pelaksanaan pengelolaan laboratorium bahasa P2B UIN Raden Mas Said Surakarta dalam meningkatkan kemahiran berbahasa mahasiswa.

\section{REFERENSI}

Fadhilah, F. (2017). Manajemen kesiswaan di sekolah. Serambi Tarbawi: Jurnal Studi Pendidikan, Riset, dan Pengembangan Pendidikan Islam, 5(2), 103-120. https://doi.org/10.32672/tarbawi.v5i $\underline{2.1274}$

Fatimah, F. N. D. (2016). Pedoman Praktis Menyusun Standard Operating Procedure. Yogyakarta: Quadrant 
Handani, W. (2019). Administrasi sarana dan prasarana. 1-4. https://doi.org/10.31227/osf.io/bwfv $\mathrm{g}$

Kartika, S., Husni, H., \& Millah, S. (2019). Pengaruh kualitas sarana dan prasarana terhadap minat belajar siswa dalam pembelajaran pendidikan agama Islam. Jurnal Penelitian Pendidikan Islam, 7(1), 113-126.

https://doi.org/10.36667/jppi.v7i1.36 $\underline{0}$

Kementerian Pendidikan dan Kebudayaan (2017). Panduan Pemanfaatan dan Pengelolaan Laboratorium Bahasa. Jakarta

Koesmadji, W., \& Adisenja, Y. H. (2004). Teknik Laboratorium. Bandung: Jurusan Pendidikan Biologi FPMIPA UPI.

Musthafa, I., dan Acep. H. (2018). Metode Penelitian Bahasa Arab. Bandung: PT. Remaja Rosadakarya.

Nurmalihah, L (2010). Pemanfaatan laboratorium bahasa Arab dan motivasi belajar siswa SMA Raudlatul Muta'allimin Tegalrejo Datinawong Babat Lamongan. Universitas Negeri Malang. Diploma thesis. Universitas Negeri Malang. http://repository.um.ac.id/91/

Priatmojo, A. S. (2019). Lab Bahasa Di Perguruan Tinggi. LPPM Universitas Semarang.

Siagian, S. P. (2011). Filsafat Administrasi. Jakarta: Bumi Aksara

Sugiyono. (2018). Metode Penelitian Kualitatif, Kuantitatif, dan $R \& D$. Badung: Alfabeta. 